\title{
The effect of breaking wave induced currents on an offshore wind turbine foundation
}

\author{
S.-J. Choi \& O.T. Gudmestad \\ Faculty of Science and Technology, University of Stavanger, Norway
}

\begin{abstract}
Several studies (Chun et al., 1999; Yoon et al., 2004) have shown that the occurrence of breaking waves over a submerged shoal can induce a jet-like strong current on the lee side of the submerged shoal, and the forces on structures following breaking waves can be perceived as wave forces being superimposed on strong current forces. In the present paper, the strong current was assumed to be induced by a breaking wave, a so-called breaking wave induced current. A MIKE $21 \mathrm{BW}$ model (MIKE $21 \mathrm{BW}, 2009)$ was established to quantify wave heights and current velocities at structural positions over a submerged shoal, and the results were compared with the results of a hydraulic model test. The wave plus current forces, the wave forces without the current, and the wave forces based on the deepwater design wave height were calculated and compared, using the wave heights and current velocities at selected structural positions. The results of numerical analysis did show that in spite of the fact that the wave heights on the lee side of the submerged shoal appeared to be small $(0.084 \sim 0.086 \mathrm{~m})$ compared with the deepwater design wave heights $(0.205 \mathrm{~m})$, a strong current $(0.277 \sim 0.448 \mathrm{~m} / \mathrm{s})$ surely occurred on the lee side of the submerged shoal due to radiation stress differentials given by the breaking of the incident waves. The comparison of the total forces on the structure without the current and with the current showed that the wave plus current forces in this area increased by an average of $280 \%$ to $300 \%$ compared with the wave forces without current. Moreover, the wave plus current forces rather exceeded the wave forces which were calculated for the deepwater design wave height $(0.205 \mathrm{~m})$.
\end{abstract}

Keywords: breaking wave induced current, submerged shoal, MIKE $21 \mathrm{BW}$, radiation stress, wave plus current force, waves and current coexisting fields. 


\section{Introduction}

For the design of an offshore wind turbine foundation installed on a flat bottom, Morison equation, utilizing a wave theory like the Stream function wave theory, has generally been employed to determine wave forces acting on the structure for a given deepwater design wave condition. However, in the case where an offshore wind turbine foundation is installed in the vicinity of a submerged shoal, the deepwater design waves may experience severe nonlinear deformations on their propagation over steep underwater steps and submerged shoals. The waves which are generated in the vicinity of the structural position may show unsymmetrical shapes or breaking patterns. Thus, calculations of wave forces can be beyond the applicable range of Morison equation and Stream function theory because of the nonlinear characteristics of the breaking wave. In addition, the occurrence of a breaking wave over the submerged shoal may induce a jet-like strong current on the lee side of the submerged shoal.

Chun et al. (1999) performed three dimensional hydraulic model tests to measure wave heights in the vicinity of a submerged shoal and wave forces on a jacket structure which was located nearby the submerged shoal. They showed that the forces on structures following breaking waves can be perceived as wave forces being superimposed on current forces. However, the currents induced by the breaking waves were not measured in their experiments even though they indirectly verified a jet-like current using some fragments of Styrofoam.

Yoon et al. (2004) simulated wave transformation and breaking wave induced current over a submerged elliptic shoal using a combined model (REF/DIF S and a current model based on the shallow water equations), and compared the results with the experimental results of Vincent and Briggs (1989). They showed that the occurrence of breaking waves over a submerged elliptic shoal could induce a jet-like current behind the submerged shoal even though wave heights rapidly decreased at the back side of the shoal. However, they did not investigate the effect of the strong current forces on a structure.

In the present paper, the jet-like current was assumed to be induced by breaking waves, a so-called breaking wave induced current. A MIKE 21 BW model was developed to quantify wave heights and current velocities at structural positions over a submerged shoal (Eardo Island, Korea), and the results were compared with the results of the hydraulic model test previously undertaken by Chun et al. (1999). Wave plus current forces, wave forces without current and wave forces based on the deepwater design wave heights were calculated and compared, using the wave heights and current velocities at selected structural positions.

\section{Brief description of MIKE $21 \mathrm{BW}$}

The MIKE 21 BW model is based on the extended Boussinesq equations of Madsen and Sørensen (1992), which can simulate the wave propagation within a depth to deepwater wavelength ratio of $h / L_{0} \leq 0.5$. The MIKE $21 \mathrm{BW}$ model can reproduce important wave phenomena occurring in a coastal region, such as 
shoaling, refraction, wave breaking, run-up and non-linear wave-current interaction (MIKE 21 BW, 2009). The wave model generates time series of wave trains by an internal wave generation technique and uses sponge layers to absorb wave energy at the model boundaries. In this paper, the $2 \mathrm{DH}$ module (two horizontal dimensions) was used.

\section{Hydraulic experiments of Chun et al. (1999)}

Chun et al. (1999) performed three-dimensional hydraulic model tests in order to estimate the wave heights in the vicinity of Eardo Island, South-West Korea, as shown in Figure 1.

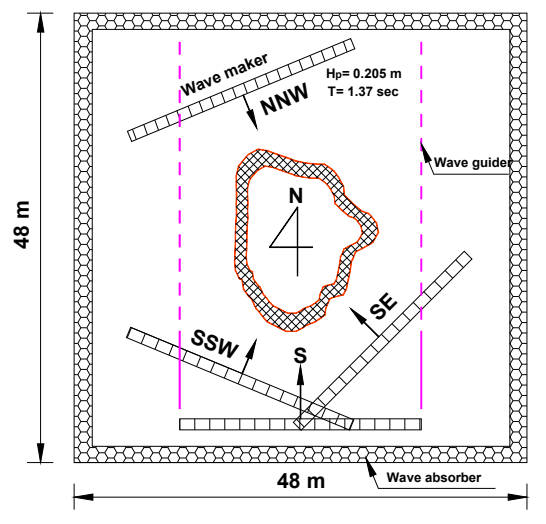

Figure 1: Plane layout of Eardo model (Small scale: 1/120)

Three-dimensional hydraulic model tests were performed at a small scale $(1 / 120)$ in a three-dimensional wave tank (48 m x $48 \mathrm{~m} \mathrm{x} 1.5 \mathrm{~m})$ at the Korea Institute of Construction Technology (Chun et al., 1999). Four wave directions were selected (NNW, SSW, S, and SE) as shown in Figure 1. The water depth was $0.489 \mathrm{~m}$ at the bottom of the tank and $0.156 \mathrm{~m}$ at the top of the Eardo Island. Wave height data were collected at lattice points (323 points) which were set up at intervals of $1 \mathrm{~m}$ in the domain for the experiments (See Figure 2). Among a total of 37 experimental conditions, a case (Wave from S-direction) shown in Table 1 were selected for the present numerical analysis.

Table 1: Selected case for the present numerical analysis

\begin{tabular}{c|c|c|c}
\hline Case & Wave type & $H_{p}(\mathbf{m})$ & $T$ (sec) \\
\hline $\mathrm{S}$ & Regular & 0.205 & 1.37 \\
\hline
\end{tabular}

Where, $H_{p}$ is the deepwater design wave height 


\section{Application of numerical analysis}

\subsection{Computational domain}

The computational domain for wave propagation was $0 \leq X \leq 16.0 \mathrm{~m}$, $0 \leq Y \leq 18.0 \mathrm{~m}$ (See Figure 2), and the grid spacing was $0.0833 \mathrm{~m}$ in both $\mathrm{X}$ and $\mathrm{Y}$ directions. Sponge layers were located to the left, right, upper, and lower sides of the computational domain with a thickness of $2 \mathrm{~L}$ (60 grids, $\mathrm{L}$ is the wave length) to absorb the wave energy. An internal wave generator was located in front of the sponge layer which was located at the lower part of the computational domain. The time step was $0.01 \mathrm{sec}$ satisfying the Courant stability condition (MIKE $21 \mathrm{BW}, 2009$ ). The model was run for 60 seconds and the final wave field was obtained by analyzing the surface elevation for the last 20 second. Table 2 shows the input conditions for the numerical analysis.

Table 2: Input conditions for the numerical analysis (Waves from S-direction)

\begin{tabular}{c|c|c|c|c}
\hline Case & $H_{p}(\mathbf{m})$ & $T$ (sec) & $\Delta x / \Delta y$ & $\Delta t$ \\
\hline $\mathbf{S}$ & $\mathbf{0 . 2 0 5}$ & 1.37 & $\mathbf{0 . 0 8 3 3 / 0 . 0 8 3 3}$ & $\mathbf{0 . 0 1}$ \\
\hline
\end{tabular}

Figure 2 shows the computational domain for the numerical analysis and wave height comparison sections (transacts 1,2 and 3) which were set up in order to compare with the results of the hydraulic model test for Case $\mathrm{S}$.

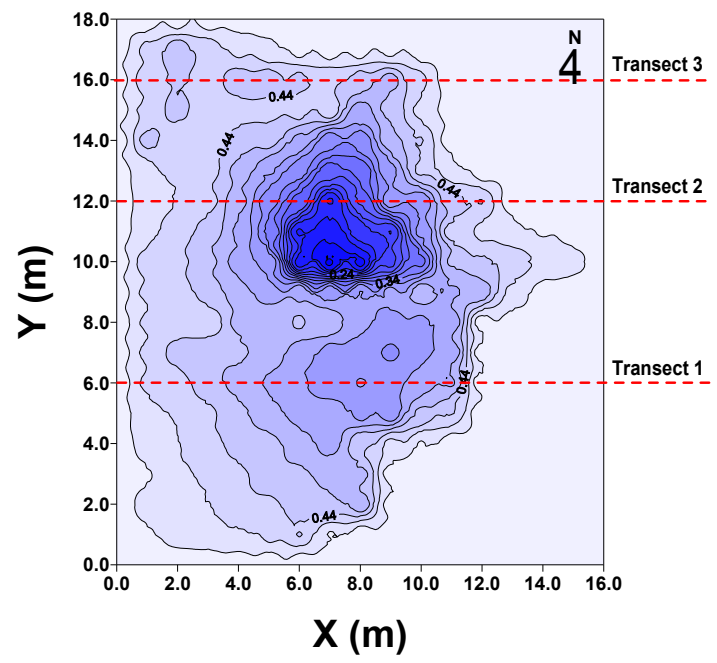

Figure 2: Computational domain and wave height comparison sections (transacts 1 to 3 ) for Case S (waves from South). The numbers represent the water depths. 


\subsection{Computational results}

\subsubsection{Wave heights and breaking wave induced current}

Figure 3 shows the contours of the measured wave heights and the calculated wave heights for Case S (waves from S-direction). Generally, the wave heights calculated by MIKE $21 \mathrm{BW}$ agreed fairly well with the measured wave heights.

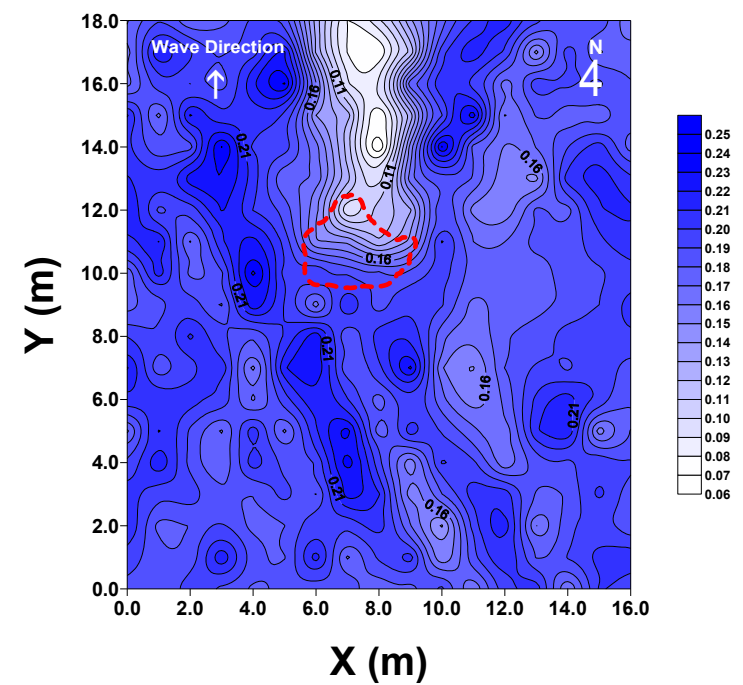

(a)

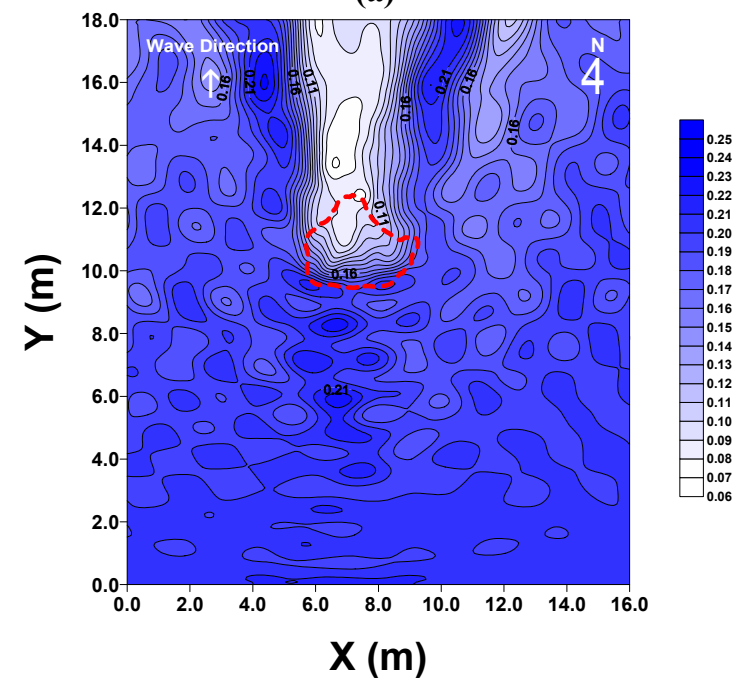

(b)

Figure 3: Contours of the measured wave heights (a) and the calculated wave heights (b) for Case S (Red dot line: Location of the submerged shoal) 
Figures 5 (a), 6 (b) and 7 (c) compares the measured wave heights with the calculated wave heights along transects $(\mathrm{Y}=6 \mathrm{~m}$ (transect 1$), \mathrm{Y}=12 \mathrm{~m}$ (transect 2), and $\mathrm{Y}=16 \mathrm{~m}$ (transect 3$)$ ). On the whole, a reasonable agreement between measured and calculated wave heights was observed. However, in some detail, the wave heights calculated by MKE 21 BW were slightly smaller than the measured wave heights at the rear side of the submerged shoal for transect 3 (See Figure 7 (c)). The reason for the discrepancy would be explained as the excessive set-up of $\Delta x$ and $\Delta y$, and application of a weekly nonlinear wave model (MIKE $21 \mathrm{BW}$ ) at fully nonlinear region. According to the results for transects 2 and 3 (See Figures 6 (b) and 7 (c)), the small wave heights were continuously observed at the central part behind the submerged shoal after breaking waves occurred in the vicinity of the submerged shoal. Moreover, a peculiarity was that somewhat larger wave heights were calculated at both sides of the smaller wave heights (See Figure 7 (c)).

On the other hand, a strong current velocity was calculated at the central part behind the submerged shoal as shown in Figure 4. This is due to the radiation stress differentials. The occurrence of breaking waves over the submerged shoal causes steep gradients of radiation stresses in the down stream direction, and the steep gradients induce strong currents along the wave direction. According to the results for transect 1 (before the breaking waves occurred, See Figure 5 (d)), the current velocities were very small as well as nearly constant. However, for transects 2 and 3 (after the breaking waves occurred, See Figure 6 (e) and 7 (f)), the current velocities increased substantially at the central part behind the submerged shoal.

Moreover, the strong currents disturb the focus of the refracted waves caused by the submerged shoal at the central part behind the submerged shoal. Yoon et al. (2004) explained this mechanism using the refraction diagrams as given in Figure 8 . The breaking waves over the submerged shoal induce strong currents along the wave direction, and the breaking wave induced currents change the direction of the refracted waves from the central part toward the outward part behind the shoal. Therefore, a concave zone appears at the central part behind the submerged shoal, and a convergence zone of the refracted waves is formed at both sides of the concave zone (Yoon et al., 2004, See Figure 8 (b)). If the strong currents do not exist behind the submerged shoal, the convergence of the waves would take place at the central part behind the submerged shoal by the encounter of the refracted waves which are generated at the left and right side of the submerged shoal (See Figure 8 (a)). For this reason, the small wave heights were continuously observed at the central part behind the submerged shoal (See Figures 3, 6 (b) and 7 (c)), and somewhat larger wave heights were observed at both sides of the smaller wave heights (See Figures 3 and 7 (c)). 


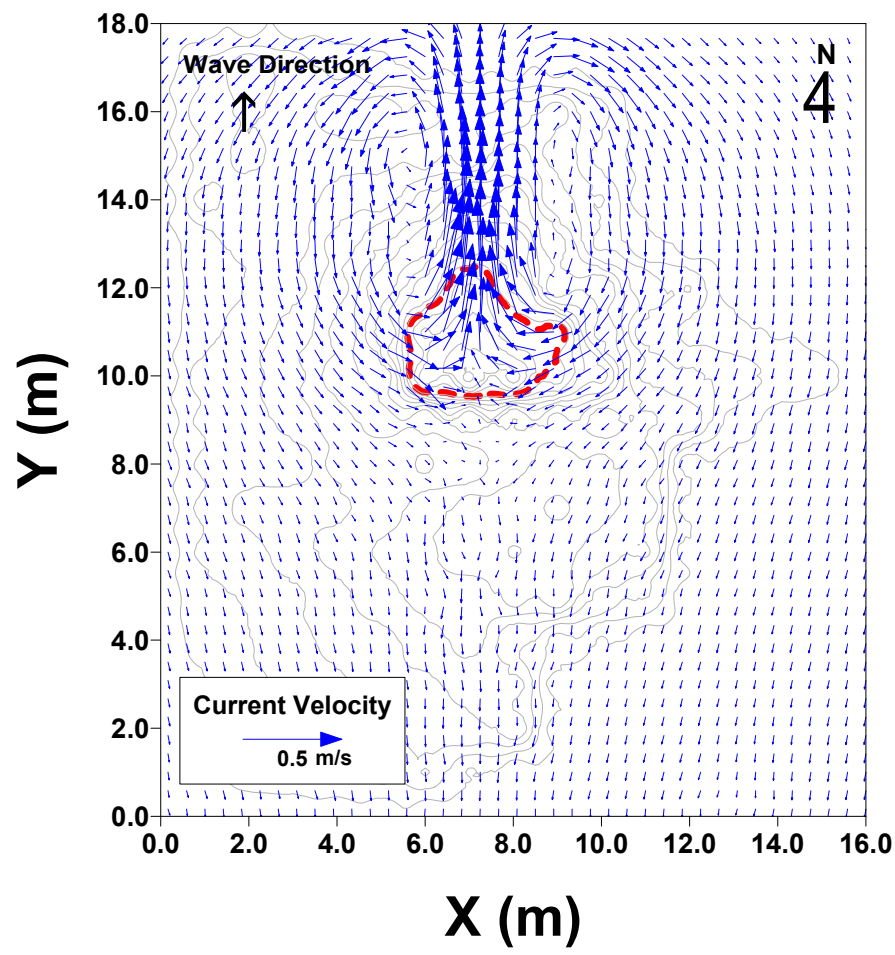

Figure 4: Vector plot of breaking wave induced current for Case S (Red dot line : Location of submerged shoal)
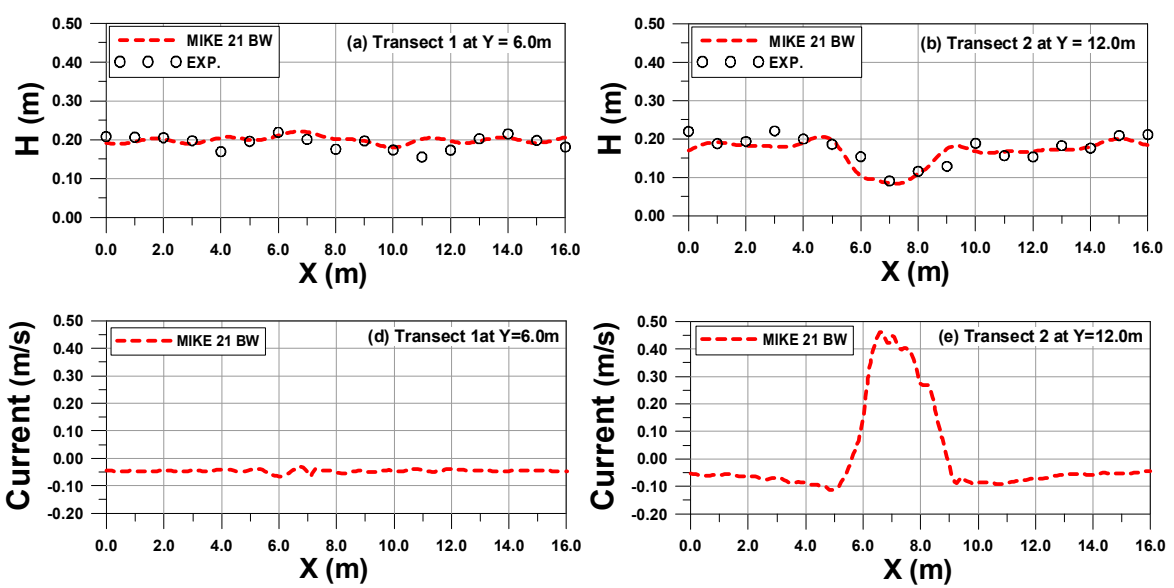

Figure 5: Wave height (top panel) and mean current profile (bottom panel) along transect 1

Figure 6: Wave height (top panel) and mean current profile (bottom panel) along transect 2 

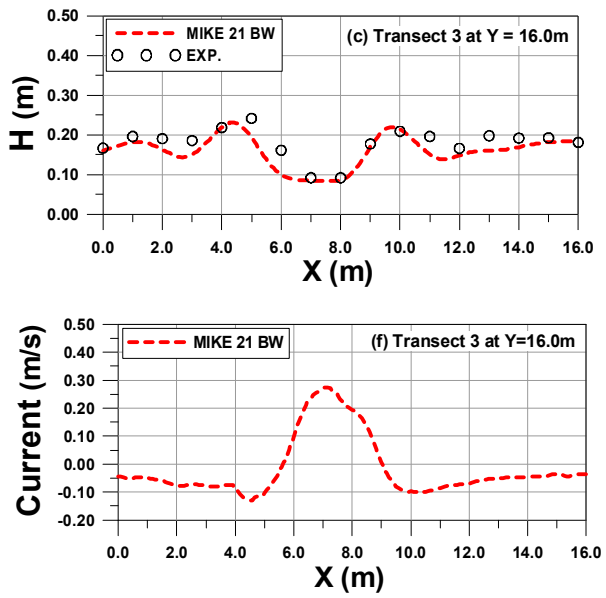

Figure 7: Wave height (top panel) and mean current profile (bottom panel) along transect 3

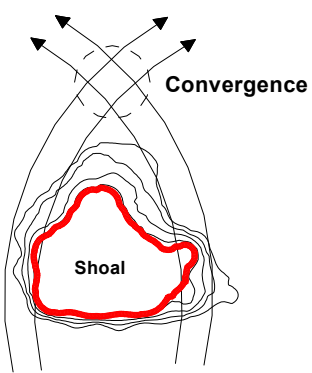

a) Without breaking wave induced current

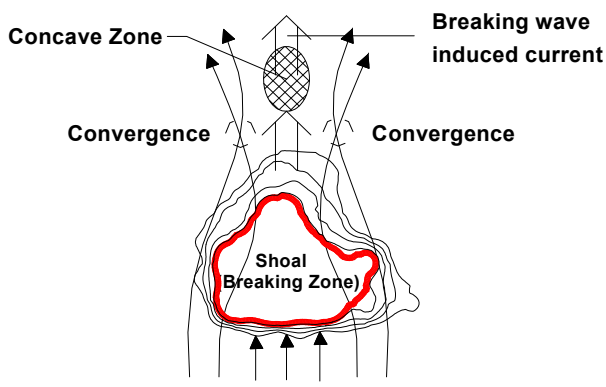

b) With breaking wave induced current

Figure 8: Schematic representation of wave breaking and refraction pattern over a shoal (Yoon et al., 2004 (Red/thick line: location of the submerged shoal)) 


\subsubsection{Variation of wave heights and current velocities at structural positions}

Figure 9 and Table 3 show the variation of the wave heights and current velocities at selected structural positions for Case S (See also Figure 10). The results show that after the breaking wave takes place, the wave heights continuously decrease; however, the current velocities continuously increase.
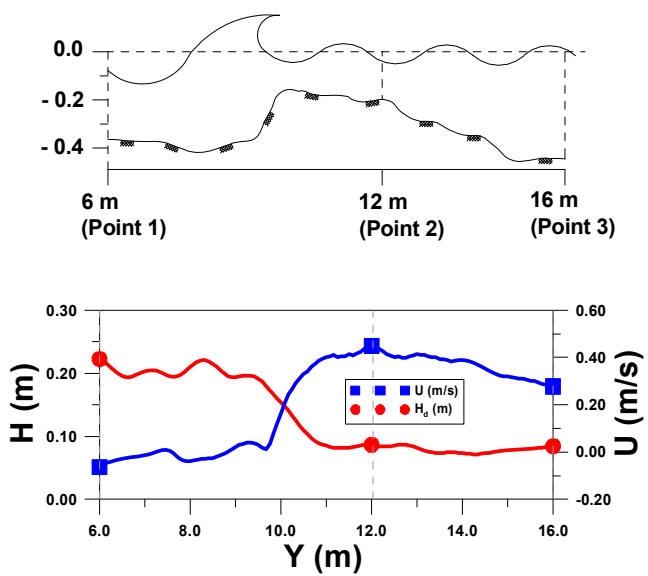

Figure 9: Variation of the wave heights and current velocities at structural positions for Case $\mathrm{S}$

Table 3: Magnitudes of the wave heights and current velocities at structural positions

\begin{tabular}{|c|c|c|c|}
\hline & Point 1 & Point 2 & Point 3 \\
\hline $\begin{array}{c}\mathrm{H}_{\mathrm{d}} \\
(\mathrm{m})\end{array}$ & 0.224 & 0.086 & 0.084 \\
\hline $\begin{array}{c}\mathrm{U} \\
(\mathrm{m} / \mathrm{s})\end{array}$ & -0.064 & 0.448 & 0.277 \\
\hline
\end{tabular}

\section{Calculation of wave plus current forces on an offshore wind turbine foundation}

\subsection{Model structure and structural positions}

The model structure is selected as a vertical cylindrical pile $(D=0.025 \mathrm{~m})$. The structural positions are adopted at three locations (point 1, point 2, and point 3 ) along the submerged shoal. Figure 10 shows the model structure and the structural positions for Case $\mathrm{S}$. 

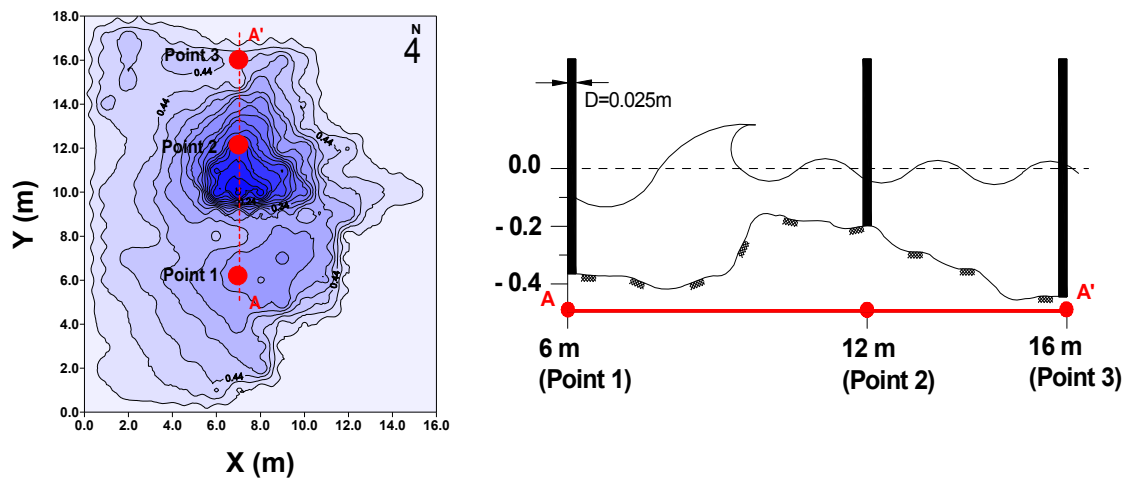

Figure 10: Model structure and structural positions for Case S (see section A-A')

\subsection{Input conditions for calculating wave plus current forces}

Input conditions for calculating wave plus current forces are adopted at the three points which are given in Figure 10. Table 4 shows the input conditions for calculating wave plus current forces for Case $\mathrm{S}$.

Table 4: Input conditions for calculating wave plus current forces for Case S

\begin{tabular}{c|c|c|c}
\hline & Point 1 & Point 2 & Point 3 \\
\hline$H_{d}(\mathrm{~m})$ & 0.224 & 0.086 & 0.084 \\
\hline$h_{d}(\mathrm{~m})$ & 0.364 & 0.197 & 0.443 \\
\hline$U_{c}(\mathrm{~m} / \mathrm{s})$ & -0.064 & 0.448 & 0.277 \\
\hline$T(\mathrm{sec})$ & \multicolumn{3}{|c}{1.37} \\
\hline $\mathrm{D}(\mathrm{m})$ & 0.025 \\
\hline$C_{D} / C_{M}$ & $1.2 / 2.0$ \\
\hline
\end{tabular}

Where, $H_{d}$ is the wave height at the structural position, $h_{d}$ is the water depth at the structural position, $U_{c}$ is the current velocity at the structural position.

\subsection{Computational results}

For the general design of an offshore wind turbine foundation, the wave forces are calculated by the given design wave conditions ( $H_{d}$ (wave height at the structural position), $T$ (wave period) and $h_{d}$ (water depth at the structural position)). However, if the offshore wind turbine foundation is installed on the lee side of a submerged shoal, the breaking wave induced current can have an important impact on the foundation. Therefore, it is necessary to exactly quantify the effects of the current forces through a comparison between wave plus current forces, wave forces without current, and wave forces based on the deepwater wave height. Figures 11 and 12 show the comparison of the wave plus current 
forces and the forces without current at points 2 and 3, respectively, for Case S. The wave plus current forces increase by about $300 \%$ and $280 \%$, respectively, compared with the wave forces without current due to the effect of the breaking wave induced currents.

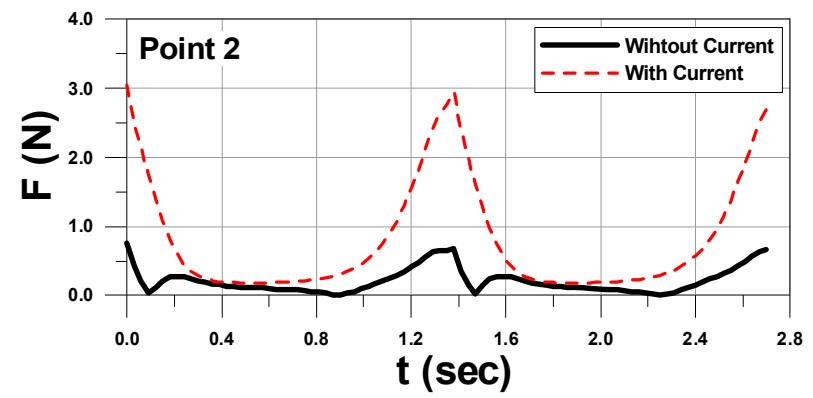

Figure 11: Comparison of the wave plus current forces and the forces without current at point 2 for Case $\mathrm{S}$

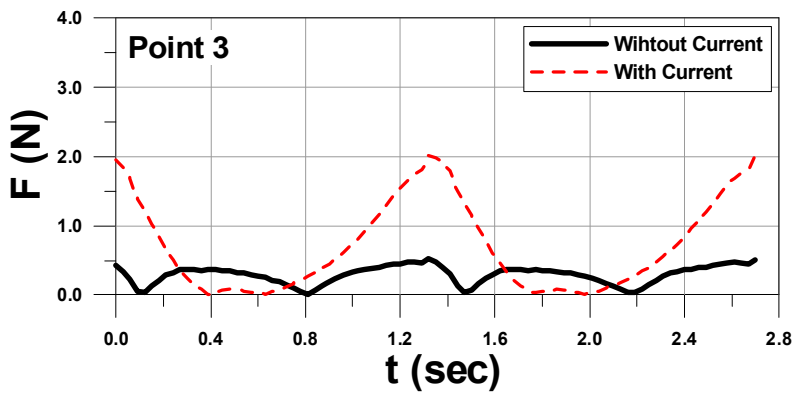

Figure 12: Comparison of the wave plus current forces and the forces without current at point 3 for Case $\mathrm{S}$

In spite of the wave height $(0.086 \mathrm{~m})$ at point 2 appearing to be small compared with the deepwater design wave height $(0.205 \mathrm{~m})$, the wave plus current forces increased by about $24 \%$ compared with the wave forces based on the deepwater design wave height $(0.205 \mathrm{~m})$ (See orange dot circle, Figure 13). For point 3, the wave forces without current are formed to be much smaller than the wave forces based on the deepwater design wave height, but the wave plus current forces are almost equal to the wave forces based on the deepwater design wave height. This would be attributed to the combined effect of waves and current induced by the breaking waves. 


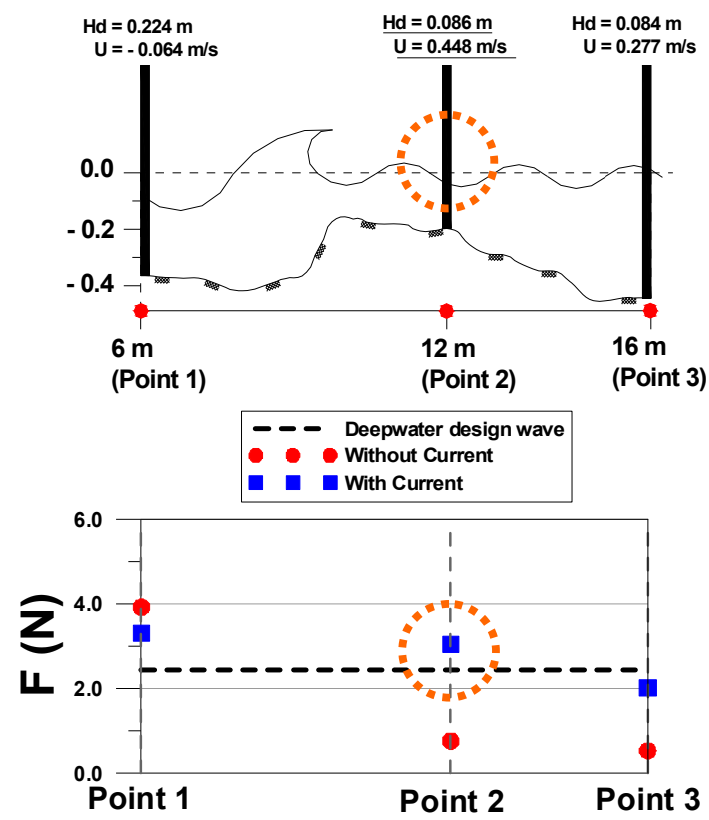

Figure 13: Comparison of wave plus current forces, wave forces without current, and wave forces based on the deepwater design wave height $(0.205 \mathrm{~m})$ at all points (points 1,2 , and 3 )

Therefore, for an offshore wind turbine foundation installed on the lee side of a submerged shoal, the use of waves only (i.e., without current velocity) could result in an under-estimated design of the structure. Moreover, in case of determination of the design wave forces on the offshore wind turbine foundation which is installed on the lee side of the submerged shoal, the maximum forces have to be selected after comparison of the wave plus current forces, wave forces without current, and wave forces based on the deepwater design wave height.

\section{Conclusions}

1. The results of numerical analysis have shown that breaking wave induced currents $(0.448 \mathrm{~m} / \mathrm{s}$, prototype scale: $5 \mathrm{~m} / \mathrm{s})$ occurred on the lee side of a submerged shoal due to radiation stress differentials given by the breaking of the incident waves.

2. Comparison of the total forces on the structure with and without the current showed that the wave plus current forces in this area increased by an average of $280 \%$ to $300 \%$ compared with the wave forces without current.

3. In spite of the wave heights $(0.086 \mathrm{~m})$ at point 2 (Figure 10) appearing to be small compared with the deepwater design wave height $(0.205 \mathrm{~m})$, the wave plus current forces increased by about $24 \%$ compared with the wave forces 
based on the deepwater design wave height. This can be attributed to the combined effect of waves and current induced by the breaking waves.

4. For an offshore wind turbine foundation installed on the lee side of a submerged shoal, the use of waves only (i.e., without the current velocity) could result in an underestimated design of the structure.

\section{Application}

The results presented in this paper are thought to be valuable for the design of any structures located on submerged shoals.

\section{References}

[1] Chun, I.S., Choi, S.J., Hong, G.H., Hwang, E.S. and Cho, I.H., 1999, Three Dimensional Hydraulic Testing of Eardo Ocean Research Station, research report submitted to Korea Ocean Research \& Development Institute, pp. 38-43.

[2] Madsen, P.A., Sørensen, O.R., 1992, "A new form of the Boussinesq equations with improved linear dispersion characteristics. Part 2, A slowly varying bathymetry", Coastal Engineering, Vol. 18, pp. 183-204.

[3] MIKE 21 BW, 2009. MIKE 21 BW: Boussinesq Waves Module User Guide, pp. 101-105, Danish Hydraulic Institute, Hørsholm, Denmark.

[4] Vincent, C.L., Briggs, M.J., 1989. Refraction- diffraction of irregular waves over a mound. Journal of Waterway, Port, Coastal and Ocean Engineering 115 (2), 269-284.

[5] Yoon, S.B., Cho, Y.-S., Lee, C., 2004. Effects of breaking-induced currents on refraction-diffraction of irregular waves over submerged shoal. Ocean Engineering 31, 633-652. 